\title{
Histogenesis of haemangioblastomas: an immunocytochemical and ultrastructural study in a case of von Hippel-Lindau syndrome
}

\author{
SEZGIN MEHMET ISMAIL, BHARAT JASANI, GILLIAN COLE \\ From the Department of Pathology, University of Wales College of Medicine, Cardiff
}

SUMMARY The cerebellar, retinal, and one of the spinal haemangioblastomas in a case of von Hippel-Lindau syndrome were studied by immunocytochemistry and electron microscopy. The tumours were positive for neurone specific enolase and variably positive for somatostatin, pancreatic polypeptide, and bombesin. Electron microscopy of the cerebellar tumour showed secretory granules with an average diameter of $170 \mathrm{~nm}$. This report is believed to be the first description of neurone specific enolase positivity and polypeptide hormones within the intervascular cells of haemangioblastomas. In the light of these findings it is suggested that haemangioblastomas are tumours of neuroectodermal origin, derived either from neural or neuroendocrine cells.

Haemangioblastomas are rare tumours which are classically found in the cerebellar hemispheres, although they may also occur in the vermis, spinal cord, medulla oblongata, cerebral hemispheres, and retina. The association of retinal, cerebellar, and spinal cord haemangioblastomas with phaeochromocytomas, renal and hepatic cysts, pancreatic islet cell tumours, ${ }^{2}$ renal cell carcinomas, and testicular cystadenomas is recognised as the von Hippel-Lindau syndrome. ${ }^{34}$ This is a rare condition which is believed to be inherited in an autosomal dominant fashion with variable penetrance.

The histogenesis of these tumours remains obscure despite much speculation and an abundance of ultrastructural and immunocytochemical studies. Endothelial, ${ }^{56}$ glial, $^{7}$ and meningeal ${ }^{8}$ origins have at various times been suggested for these tumours, although firm supportive evidence has not been forthcoming.

In view of the other endocrine associations of the von Hippel-Lindau syndrome, several haemangioblastomas from a patient with this condition were studied with electron microscopy and immunocytochemistry using antisera to neurone specific enolase and selected polypeptide hormones.

Accepted for publication 19 December 1984

\section{Case report}

A 49 year old woman with a history of retinal angiomatosis and a family history of brain tumours was admitted to hospital with a severe headache followed by respiratory arrest. Despite intensive respiratory and circulatory support she died two days after admission. The clinical features of this case have been reported in detail elsewhere."

\section{PATHOLOGICAL FINDINGS}

Postmortem examination revealed a glass eye on the right side. The brain was diffusely oedematous with symmetrical dilatation of both lateral ventricles and herniation of both cerebellar tonsils. A subarachnoid haemorrhage was present in the posterior fossa, which extended subdurally down the spinal cord. The spinal cord and its nerve roots appeared macroscopically normal. Within the right lobe of the cerebellum there was a ruptured haemorrhagic cystic tumour with a vascular mural nodule. There was a yellow cortical nodule $1.5 \mathrm{~cm}$ in diameter within the right kidney, which also contained multiple cysts filled with serous fluid; the largest of these was at the upper pole and $7 \mathrm{~cm}$ in diameter. The liver contained a $1.5 \mathrm{~cm}$ cyst filled with serous fluid. The left adrenal weighed $10 \mathrm{~g}$ and contained a yellow nodule $1.5 \mathrm{~cm}$ in diameter at one pole. The right adrenal, weighing $45 \mathrm{~g}$, was completely replaced by a haemorrhagic multilobular tumour. 


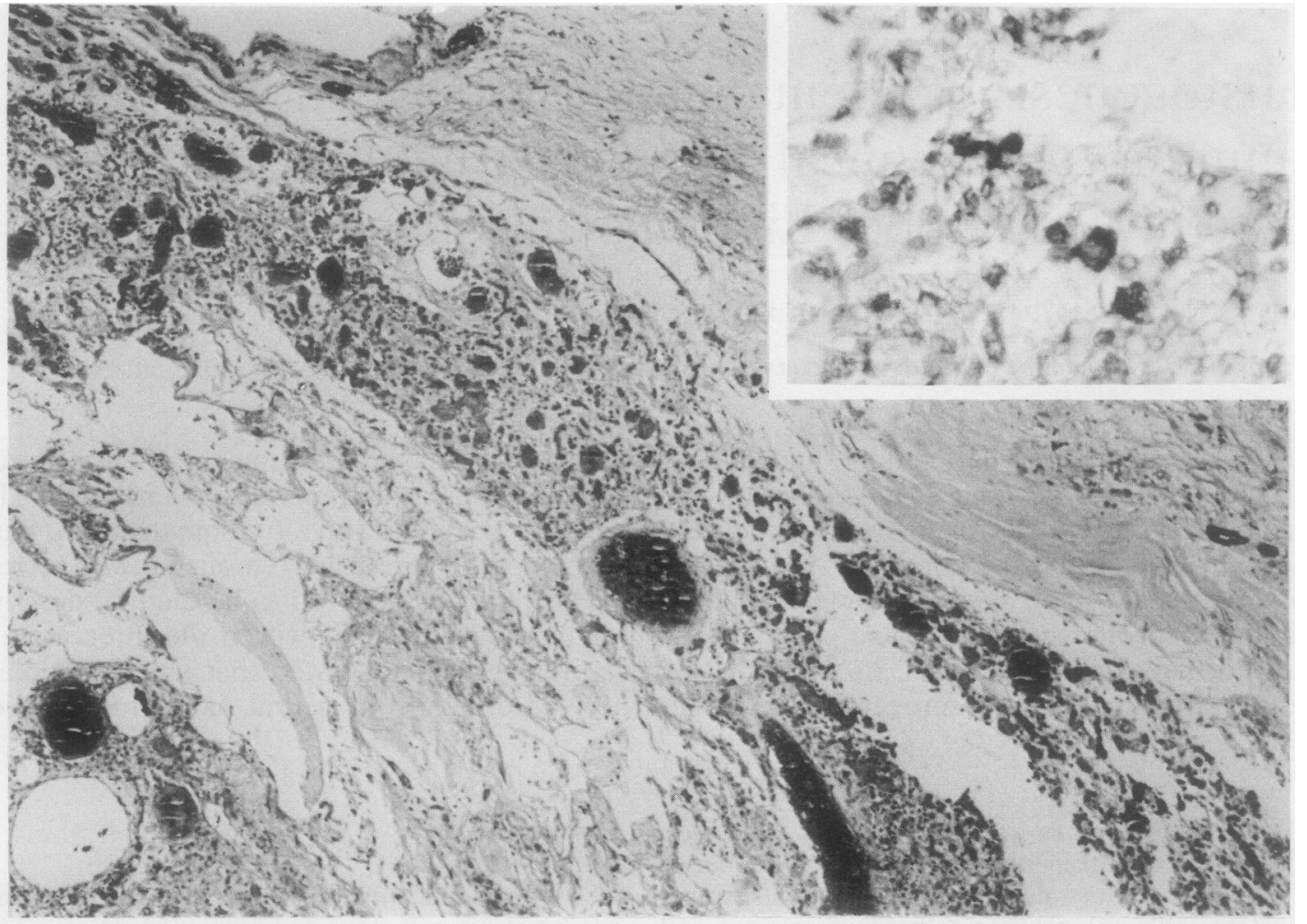

Fig. 1 Retinal haemangioblastoma. Haematoxylin and eosin. $\times 20$. Inset. Retinal haemangioblastoma showing strong immunoperoxidase staining for neurone specific enolase. $\times 125$. Note the absence of immunoreactivity in the endothelial cells lining the vascular space (top right).

\section{Microscopical findings}

Sections of the mural nodule within the cerebellar tumour showed the typical features of a cerebellar haemangioblastoma. The tumour was composed of thin walled endothelium lined vascular channels of varying sizes and polygonal intervascular or stromal cells showing some nuclear pleomorphism. The stromal cells had abundant cytoplasm which was eosinophilic and finely granular in some cells but vacuolated in others. Sections of the left eye revealed a retinal haemangioblastoma (Fig. 1), which incorporated some hyaline interstitial material but was otherwise similar to the cerebellar lesion. Multiple sections of the spinal cord showed several microscopic haemangioblastomas on the posterior nerve roots in the cervical, thoracic, and lumbar regions. The largest of the spinal tumours was macroscopically visible at $3 \mathrm{~mm}$ diameter (Fig. 2). The spinal haemangioblastomas were similar in appearance to the cerebellar tumour except for the presence of interstitial hyaline material in the largest spinal tumour.

The left adrenal tumour was a clear cell cortical adenoma; the right adrenal tumour was a phaeochromocytoma. The yellow renal nodule was a clear cell tumour, while the renal and hepatic cysts were benign simple cysts.

The necropsy findings were thus those of the von Hippel-Lindau syndrome.

\section{Material and methods}

Immunocytochemistry was performed on formalin fixed, paraffin embedded tissue using the hapten $O$ labelled antibody bridge method. ${ }^{1011}$ The cerebellar and the retinal haemangioblastoma and the largest of the spinal tumours were studied in this way using antisera to neurone specific enolase $(1 / 1600)$, bombesin $(1 / 800)$, pancreatic polypeptide $(1 / 100)$, and somatostatin $(1 / 200)$. The antisera to bombesin and pancreatic polypeptide were kindly donated by Dr J Polak, Hammersmith Hospital, and that to neurone specific enolase by Dr R Thompson, Cambridge. The antiserum to somatostatin was purchased from RIA (UK) Ltd. The antisera were applied to the sections at $4^{\circ} \mathrm{C}$ for $15 \mathrm{~h}$. 


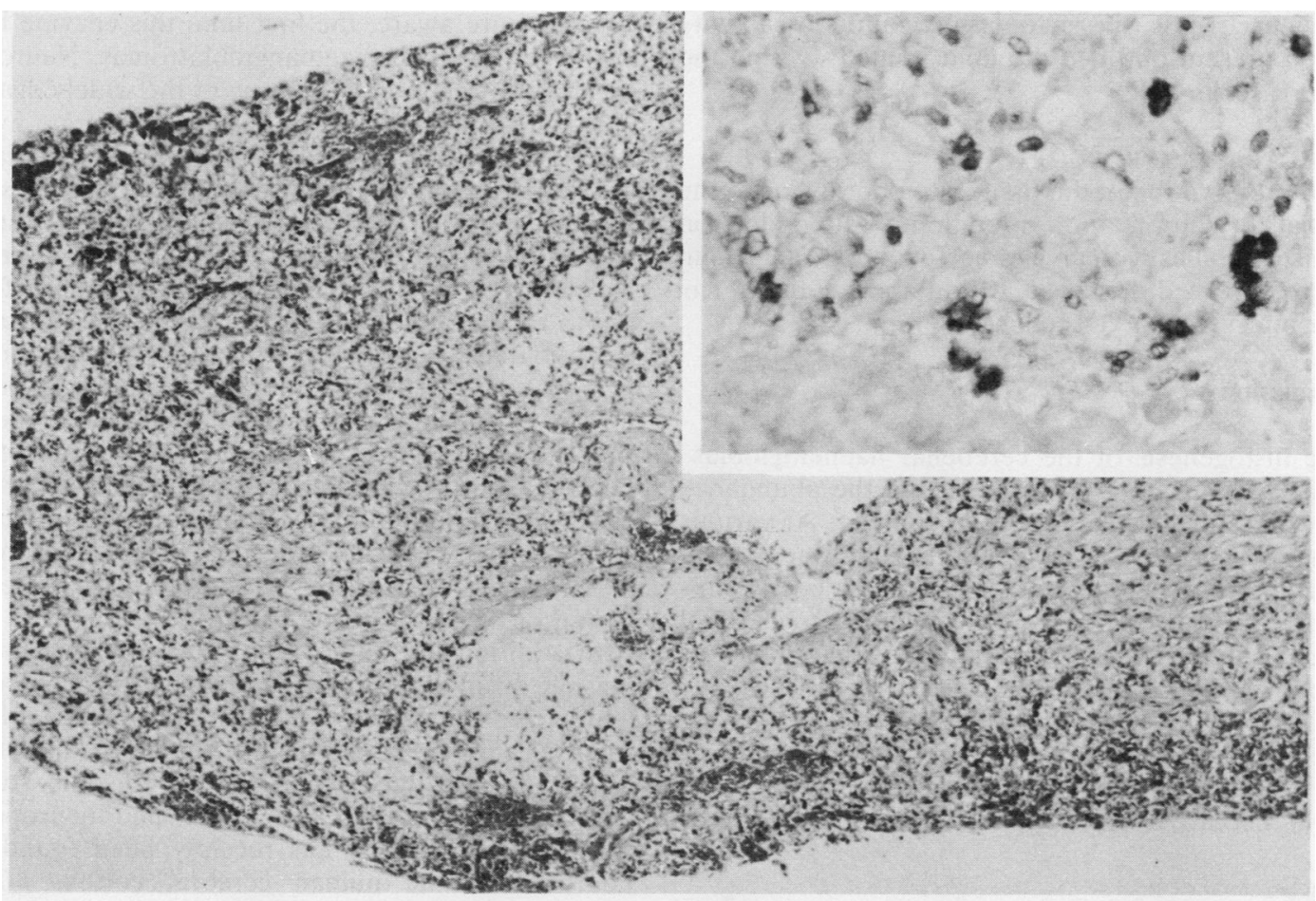

Fig. 2 Spinal haemangioblastoma of dorsal nerve root. Haematoxylin and eosin. $\times 20$. Inset. Spinal nerve root haemangioblastoma showing strong immunoperoxidase staining for bombesin. $\times 125$

The specificity of the antisera was confirmed by the use in each case of appropriate control tissues. In the case of neurone specific enolase positive staining was shown -within the autonomic nerves in the small bowel wall. Granular cytoplasmic immunoreactivity to bombesin was seen within appropriate cells in the gastric pits. Sections of pancreas were used to confirm granular cytoplasmic immunoreactivity to somatostatin within some islet cells, while pancreatic polypeptide positivity was present both within occasional islet cells and scattered parenchymal cells. A negative control, omitting the primary antibody, was performed in each case to monitor non-specific background staining.

For electron microscopy, wet formalin fixed tissue from the cerebellar haemangioblastoma was refixed in glutaraldehyde, postfixed in osmium tetroxide, and block stained in uranyl acetate. The tissue was then embedded in Epon 812 and the ultrathin section stained on the grid with lead citrate.

\section{Results}

IMMUNOCYTOCHEMISTRY

Cerebellar haemangioblastoma

About half of the intervascular cells showed weak diffuse cytoplasmic immunoreactivity with the antiserum to neurone specific enolase. A similar proportion of cells showed granular cytoplasmic staining with the antisera to somatostatin and bombesin. No cytoplasmic immunoreactivity was found with the antiserum to pancreatic polypeptide.

\section{Retinal haemangioblastoma}

All the intervascular cells showed strong diffuse cytoplasmic immunoreactivity to neurone specific enolase (Fig. 1 inset), while three quarters of the cells showed strong granular cytoplasmic staining with the antisera to somatostatin and bombesin and half of them showed granular cytoplasmic staining with the antiserum to pancreatic polypeptide.

\section{Spinal haemangioblastoma}

About a third of the intervascular cells showed strong diffuse cytoplasmic staining for neurone specific enolase, with a similar proportion exhibiting strong granular cytoplasmic immunoreactivity to somatostatin and bombesin (Fig. 2 inset). No staining was seen with the antiserum for pancreatic polypeptide. 
In each case the cytoplasmic immunoreactivity when present outlined the lipid vacuoles within the intervascular cells.

\section{ELECTRON MICROSCOPY}

The preservation of the tissue was poor owing to the initial formalin fixation. Membrane bound electron dense granules with an average diameter of $170 \mathrm{~nm}$ were observed, however, within about a quarter of the intervascular cells (Fig. 3).

\section{Discussion}

The histogenesis of the cerebellar haemangioblastoma remains controversial despite the abundance of work and speculation on the subject. At various times a vascular, reticuloendothelial, ${ }^{12}$ meningeal, glial, or neuroectodermal ${ }^{1314}$ origin has been proposed for these tumours. The immunocytochemical findings in this case of von Hippel-Lindau syndrome support a neuroectodermal origin.

The demonstration of cytoplasmic neurone specific enolase immunoreactivity in the intervascular cells of all three haemangioblastomas studied from this case of von Hippel-Lindau syndrome is, as

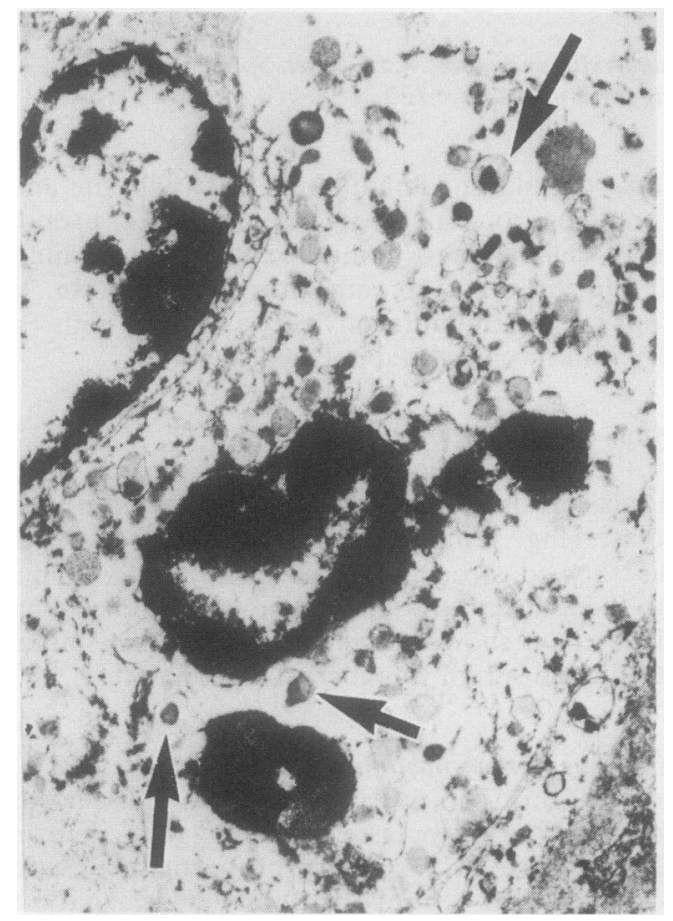

Fig. 3 Electron micrograph of cerebellar haemangioblastoma showing membrane bound granules (arrowed). $\times 10200$ far as we are aware, the first time this enzyme has ever been noted in haemangioblastomas. Neurone specific enolase is an isoenzyme of the widely distributed dimeric enzyme 2-phospho-D-glycerate hydrolase, commonly referred to as enolase. Enolase has three immunologically distinct subunits designated $\alpha, \beta$ and $\gamma$; five types of isoenzyme, the three homodimers $(\alpha \alpha, \beta \beta, \gamma \gamma)$ and two hybrids $(\alpha \beta, \alpha \gamma)$, have been identified. ${ }^{15}$ The enzyme commonly referred to as neurone specific enolase is $\gamma \gamma$ enolase and is found in central neurones, ${ }^{16}$ peripheral autonomic nerves, ${ }^{17}$ and cells of the diffuse endocrine system. ${ }^{17-19}$ Neurone specific enolase has also been shown within rat and rhesus monkey pinealocytes, pituitary cells, and hypothalamic neuroendocrine cells. Our finding of neurone specific enolase immunoreactivity in the haemangioblastomas studied therefore suggests that these lesions are of neural or neuroendocrine origin.

In addition, this study has shown variable cytoplasmic positivity to selected polypeptide hormones within the intervascular cells of the haemangioblastomas examined. Somatostatin, bombesin, and pancreatic polypeptide were selected for this study because the first two are established neuropeptides $^{2021}$ and the last has recently been found in neurones of the human cerebral cortex. ${ }^{22}$ Our finding of cytoplasmic immunoreactivity to these hormones within the haemangioblastomas examined suggests that a primitive peptidergic neurone may be the cell of origin of the haemangioblastoma. This conclusion is given some support by the fact that all the spinal haemangioblastomas in this case occurred in the dorsal nerve roots. Previously reported cases ${ }^{23}$ of cerebellar haemangioblastoma accompanied by spinal haemangioblastomas have sought to explain the latter as metastases; however, the occurrence within the dorsal nerve roots of all the spinal haemangioblastomas makes this explanation unlikely in our case. It is therefore suggested that these tumours occurred in the posterior nerve roots because they originated from structures within the dorsal root ganglia, possibly primitive peptidergic neurones.

The present study confirms the presence in the intervascular cells of the haemangioblastoma of membrane bound electron dense granules first reported by Ishwar $e^{t} a^{24}$ in two of the multiple supratentorial haemangioblastomas in their patient. The granule size in their case varied from 120 to 200 $\mathrm{nm}$. Both the granule containing tumours showed foci of extramedullary haemopoiesis, and as erythropoietin secretion is a recognised association of the haemangioblastoma $a^{25} 26$ these authors speculated that these secretory granules could represent erythropoietin. More recently, Andrioli et $a^{27}$ have 
observed electron dense particles 200-500 nm diameter in the cytoplasm of the intervascular cells in one of the three haemangioblastomas they examined ultrastructurally; these authors likewise assumed that the granules represented erythropoietin. But while there is considerable controversy regarding the mechanism of production of erythropoietin, there is as yet no evidence that this substance occurs in the form of membrane bound granules. ${ }^{28}$ Our finding of membrane bound granules with an average diameter of $170 \mathrm{~nm}$ is in keeping with that of Ishwar et al, and our immunocytochemical findings raise alternative possibilities for granule content.

The demonstration of immunoreactivity for several polypeptide hormones within intervascular cells of the same haemangioblastoma requires some discussion. We have not in this study sought to establish whether the hormones occurred in the same or in different tumour cells. The occurrence of more than one neuroactive substance in a single neurone is, however, a well known phenomenon both in humans and other mammals. ${ }^{22}{ }^{2 y}$ Our findings are therefore entirely in keeping with the suggested origin of the haemangioblastoma from a primitive peptidergic neurone. The multiple haemangioblastomas seen in the von Hippel-Lindau syndrome presumably represent multifocal neoplasia. The presence of multiple hormones within a single tumour cell could then be explained on the basis of derivation from a primitive cell with the ability to secrete several polypeptide hormones. Another possibility that should be considered is that of multinodular hyperplasia with a polyclonal cell population within each haemangioblastoma.

It may be that the multiple haemangioblastomas found in the von Hippel-Lindau syndrome arise from nests of primitive neural cells which persist into adult life after disturbed embryonic development. Further work is required to confirm or refute the existence of such a precursor lesion, to elucidate the nature of the ultrastructurally observed secretory granules, and to define further the cell of origin of this most enigmatic tumour.

\section{References}

' Hull MT, Wastel KA, Muller J, Higgins JT. Familial islet cell tumours in von Hippel-Lindau's disease. Cancer 1979;44:1523-6.

2 Probst A, Lotz M, Heitz PL. Von Hippel-Lindau's disease, syringomyelia and multiple endocrine tumours: A complex neuroendocrinopathy. Virchows Arch $[A]$ Pathol Anat 1978;378: 265-72.

${ }^{3}$ Hoston WA, Wong V, Eldridge R. Von Hippel-Lindau disease. Clinical and pathological manifestations in nine families with 50 affected members. Arch Intern Med 1976; 136:769-77.

4 Melmon KL, Rosen SW. Lindau's disease. Review of the literature and study of a large kindred. Am J Med 1964;36:595617.

- Silver ML. Hennigar G. Cerebellar haemangioma (haemangioblastoma). A clinico-pathological review of 40 cases. J
Neurosurg 1952;9:484-94

- Jurno S, Nadji M, Harvey DG, Parker JC, Font RL, Mordes AR. Haemangioblastomas: histogenesis of the stromal cell studied by immunocytochemistry. Hum Pathol 1982;13:13-8.

7 Jakobiec FA, Font RL, Johnson FB. Angiomatosis retinae. An ultrastructural study and lipid analysis. Cancer 1976;38:2042-56.

${ }^{8}$ Russell DS, Rubinstein LJ. Pathology of tumours of the nervous system. 4th ed. London: Edward Arnold Ltd 1977:120-5.

' Ismail SM, Cole G. Von Hippel-Lindau syndrome with microscopic haemangioblastomas of the spinal nerve roots. A case report. J Neurosurg 1984;60:1279-81.

10 Jasani B, Wynford-Thomas D, Williams ED. Use of monoclonal antihapten antibodies for immunolocalization of tissue antigens. J Clin Pathol 1981;34:1000-2.

11 Jasani B, Thomas ND, Newman GR, Williams ED. DNP-hapten sandwich staining (DHSS) procedure: design, sensitivity, versatility and applications. Immunology Communications 1983;12:57.

${ }^{12}$ Olivecrona $\mathrm{H}$. The cerebellar angioreticulomas. J Neurosurg 1952;9:317-30.

${ }^{13}$ Chapman RC, Diaz-Perez R. Phaeochromocytoma associated with cerebellar haemangioblastoma. Familial occurrence. JAMA 1962;182: 1014-7.

${ }^{14}$ Sander S, Normann T, Martinsen W. Phaeochromocytoma associated with von Hippel-Lindau's disease in a family. Scand J Urol Nephrol 1971;4:259-63.

is Royds JA, Parsons MA, Taylor CB, Timperley WR. Enolase isoenzyme distribution in the human brain and its tumours. $J$ Pathol 1982; 137:37-49.

${ }^{16}$ Schmechel D, Marangos PJ, Zis AP, Brightman M, Goodwin FK. Brain enolases as specific markers of neuronal and glial cells. Science 1978;199:313-5.

${ }^{17}$ Bishop AE, Polak JM, Facer P, et al. Neuron specific enolase: A common marker for the endocrine cells and innervation of gut and pancreas. Gastroenterology 1983;83:902-15.

${ }^{1 *}$ Schmechel D, Marangos PJ, Brightman M. Neurone-specific enolase is a molecular marker for peripheral and central neuroendocrine cells. Nature 1978;276:834-6.

${ }^{14}$ Tapia FJ, Barbrosa AJA, Marangos PJ, et al. Neuron-specific enolase is produced by neuroendocrine tumours. Lancet 1981;i:808-11.

${ }^{20}$ Krieger DT, Martin JB. Brain peptides. $N$ Engl J Med 1981;304:876-85.

${ }^{21}$ Bloom SR, Polak JM. Gut hormones. 2nd ed. Edinburgh: Churchill Livingstone, 1981:457-63.

${ }^{22}$ Vincent SR, Johansson O, Hokfelt T, et al. Neuropeptide coexistence in human cortical neurones. Nature 1982;298:65-7.

${ }^{23}$ Mohan J, Brownell B, Oppenheimer DR. Malignant spread of haemangioblastoma: report on two cases. J Neurol Neurosurg Psychiatry 1976;39:515-25.

24 Ishwar S, Taniguichi RM, Vogel FS. Multiple supratentorial haemangioblastomas. Case study and ultrastructural characteristics. J Neurosurg 1971;35:396-405.

is Cramer F, Kimsey WH. The cerebellar haemangioblastomas: review of 53 cases with special reference to cerebellar cysts and association of polycythaemia. Arch Neurol Psychiatry 1952; 67:237-52.

26 Jeffreys RV, Napier JAF, Reynolds SH. Erythropoietin levels in posterior fossa haemangioblastoma. J Neurol Neurosurg Psychiatry 1982;45:264-6.

${ }^{27}$ Andrioli GC. Scarini I. Intrinsic haematopoietic activity of cerebellar haemangioblastomas. Ultrastructural study of three cases. Neurochirurgia 1979;22:24-38.

${ }^{2 *}$ Graber SE, Krantz SB. Erythropoietin and the control of red cell production. Ann Rev Med 1978;29:51-66.

${ }^{24}$ Hokfelt T, Johannson O, Ljungdahl A, Lundberg JM, Schultzberg M. Peptidergic neurones. Nature 1980;284:515-21.

Requests for reprints to: Dr SM Ismail, Department of Pathology, University Hospital of Wales, Heath Park, Cardiff, CF4 4XW, Wales. 